\title{
Avaliação da usabilidade de um portal de comercialização para agricultura familiar
}

Usability Evaluation of a family farming marketing portal

SIMÕES, Aliana Pereira; Mestre em Design; Incaper

aliana.simoes@incaper.es.gov.br

AOKI, Pierângeli Cristina Marim; Mestre em Ciências Biológicas e Especialista em Gerenciamento de Projetos; Incaper

pieraaoki@incaper.es.gov.br

\section{Resumo}

Este presente artigo descreve a aplicação do método de Avaliação Cooperativa para avaliar a usabilidade de um portal web de comercialização para o desenvolvimento da agricultura familiar do Estado do Espírito Santo. A avaliação foi realizada com um grupo de agricultores familiares e demonstrou resultados significativos para a melhoria do design e da usabilidade deste portal.

Palavras Chave: Usabilidade; Design; Ergonomia e Agricultura Familiar.

\begin{abstract}
This article describes the application of the Cooperative Evaluation method to evaluate the usability of a commercial web portal for the development of family agriculture in the Espirito Santo State. The evaluation was carried out with a group of family farmers and demonstrated significant results to improve the design and usability of this portal.
\end{abstract}

Keywords: Usability; Design; Ergonomic and Family Farming. 


\section{Introdução}

Segundo dados do Instituto Brasileiro de Geografia e Estatísitica - IBGE (2006), 80\% dos estabelecimentos rurais do Espírito Santo são de agricultores familiares, sendo estes responsáveis por $44 \%$ da riqueza produzida no Estado, o que gera mais de 200 mil postos de trabalho. Aliadas a essas informações, o Plano Estratégico da Agricultura Capixaba - Pedeag 3 (2015 - 2030), documento de planejamento e gestão elaborado pela Secretaria Estadual de Agricultura, Abastecimento, Aquicultura e Pesca do Estado do Espírito Santo (Seag), pelo Instituto Capixaba de Pesquisa, Assistência Técnica e Extensão Rural (Incaper) e parceiros, verificou que a agricultura familiar é a maior força de trabalho do agronegócio do Estado e os agentes (produtores, empresas e serviços) possuem uma visão alinhada sobre a importância dos desafios para a agropecuária até o ano de 2030.

É fato que a base econômica da maioria dos municípios do interior do Estado do Espírito Santo é oriunda da agricultura familiar e, apesar de grande parte da produção agrícola capixaba ser baseada nas unidades produtivas dos agricultores familiares, muitos têm dificuldade para realizar a gestão das suas propriedades e produção. Diante desse cenário e com vistas a auxiliar a comercialização dos produtos e serviços da agricultura familiar de todas as regiões do Estado, foi executado pelo Incaper o Projeto Estruturação e Fortalecimento dos Setores Produtivos da Agricultura Familiar do Norte do Espírito Santo - Projeto Tecsocial. Este projeto foi desenvolvido em parceria com a Secretaria de Estado de Ciência e Tecnologia, Inovação e Educação Profissional - SECTI, com apoio do Ministério da Ciência e Tecnologia, Inovação e Comunicações - MCTIC, da Financiadora de Estudos e Projetos - Finep e do Conselho Nacional de Desenvolvimento Científico e Tecnológico - CNPq.

O objetivo do projeto foi identificar, adequar e aplicar tecnologias sociais para estruturar as organizações associativas dos agricultores familiares e a gestão de suas unidades produtivas e empreendimentos rurais, bem como, incentivar a agregação de valor, a diversificação de produtos e serviços e a comercialização de seus produtos, visando o acesso e a fidelização de mercados diferenciados e dos clientes. Dentro das atividades desenvolvidas foi criado o Portal Web de Comercialização de Produtos e Serviços da Agricultura Familiar, que está em fase de desenvolvimento e ainda não tem um nome fantasia definido. Portanto, o artigo descreve como a aplicação dos testes de usabilidade está auxiliando no desenvolvimento de uma interface digital mais funcional, fácil de usar e eficiente que futuramente poderá ser uma das ações mais importante para o desenvolvimento da comercialização agrícola capixaba.

\section{Delineamento da pesquisa}

Esta pesquisa vai ao encontro de alguns pesquisadores que estudam o design, a comunicação rural, a usabilidade e a ergonomia. Um estudo sobre cada uma dessas áreas pode contribuir muito com o sucesso do Portal Web de Comercialização dos Produtos e Serviços da Agricultura Familiar Capixaba.

Norman (2006) considera o design como um ato de comunicação, e defende que um bom design é o resultado de um conhecimento do público para qual o designer está se comunicando. Esta afirmação de Norman corresponde aos ensinamentos de Frederich (1988) que estuda a comunicação rural e descreve que as ações para a melhoria dessa forma de comunicação devem ter uma abordagem centrada na pessoa. Este autor destaca que os agricultores familiares devem ser sujeitos ativos no processo de comunicação. $O$ autor também sugere que a comunicação rural 
deve procurar métodos e técnicas que favoreçam essa humanização. É nesse ponto que entra a contribuição da ergonomia e da usabilidade.

Moraes e Montalvão (2007) descrevem a ergonomia como uma ciência que está relacionada ao entendimento das interações entre os seres humanos e outros sistemas. De acordo com as autoras, é necessário que estes sistemas sejam projetados a partir do ponto de vista do usuário. A ergonomia oferece ferramentas para auxiliar no conhecimento da formação cultural e social do usuário com o objetivo de analisar os impactos do processo de interação. Nessa linha, conforme Moraes (2001), a ergonomia dispõe de métodos e técnicas que permitem avaliar a usabilidade de um produto e verificar se ele dispõe de um bom design.

Segundo Montalvão (2008), a aplicação dos princípios da ergonomia aos processos de design resulta em um produto mais atrativo e amigável, características que norteiam o campo da usabilidade. O objetivo da avaliação da usabilidade é verificar se o produto é efetivo, eficiente e satisfatório, o que vai ao encontro do que foi preconizado anteriormente.

Conforme o contexto teórico apresentado, a presente pesquisa delimita os seguintes objetivos para avaliar a relação dos usuários agricultores familiares com o Portal Web: verificar se o design do portal está satisfatório, conhecer as características culturais desses usuários, melhorar o processo de comunicação desses usuários com a tecnologia do portal, observar se esses usuários conseguem atingir todos os objetivos de interação com o portal, verificar os esforços realizados pelos usuários para realizar uma determinada tarefa e avaliar o nível de satisfação dos usuários ao utilizar o portal.

\section{Objeto da Pesquisa}

O Portal Web (Figura 1) tem quatro tipos de usuários bem distintos: o agricultor familiar, o comprador de produtos agrícolas, o servidor do Incaper e parceiros e, o administrador do portal. 0 agricultor tem como ações realizar um cadastro do perfil, anunciar seu (s) produto (s), serviço (s), preço (s), contato (s) e evento (s) temático (s), o que impulsiona a venda direta de seus produtos aos diferentes consumidores. Também há uma funcionalidade chamada Frete Solidário, que propicia a interlocução entre os agricultores familiares para que compartilhem fretes, diminuam custos e aperfeiçoem a logística de distribuição de seus produtos, principalmente aos mercados institucional e tradicional. O comprador verifica os produtos que foram anunciados e também faz uma oferta de compra direta. O servidor do Incaper é responsável em liberar os acessos dos agricultores e fornecedores, além de verificar a comercialização ocorrida dentro do portal, podendo gerar relatórios com essa informação. $O$ administrador será responsável em inserir todo o conteúdo sobre o portal no banco de dados, cadastrar e validar os usuários no sistema, e realiza a manutenção do portal em geral.

Inicialmente, para esta pesquisa selecionou-se os perfis de agricultores familiares, servidores e parceiros, principalmente das Prefeituras Municipais. Mas durante o processo da avaliação do préteste percebeu-se que o usuário agricultor familiar teve mais dificuldade de interação com a ferramenta do que o usuário servidor/parceiro. Por essa razão, os resultados apresentados estão pautados nos resultados da pesquisa realizada apenas com os agricultores familiares. 
Figura 1 - Página Principal do Portal de Comercialização

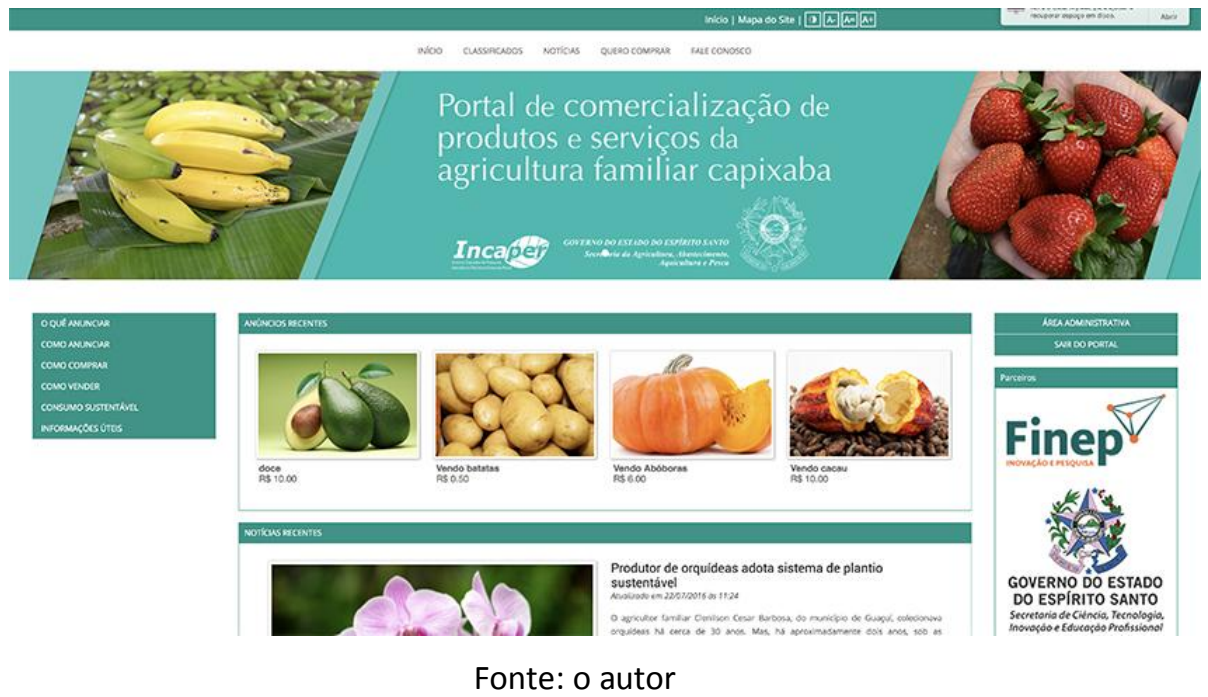

\section{Perfil do Usuário}

O público beneficiário principal é o agricultor familiar, que de acordo com a lei no 11.326 que estabelece as diretrizes para a formulação da Política Nacional da Agricultura Familiar e de acordo com essa Lei, o agricultor familiar e empreendedor familiar rural é aquele que pratica atividades no meio rural, atendendo, simultaneamente, aos seguintes requisitos: I - não detenha, a qualquer título, área maior do que quatro módulos fiscais; II - utilize predominantemente mão-de-obra da própria família nas atividades econômicas do seu estabelecimento ou empreendimento; III - tenha renda familiar predominantemente originada de atividades econômicas vinculadas ao próprio estabelecimento ou empreendimento; IV - dirija seu estabelecimento ou empreendimento com sua família. São beneficiários desta Lei: agricultores e aquicultores de base familiar, silvicultores, extrativistas, pescadores artesanais, ribeirinhos, acampados, assentados da Reforma Agrária e Povos e Comunidades Tradicionais, com destaque no Estado para os indígenas, quilombolas e pomeranos, todos assistidos tecnicamente pelo Incaper.

Foi criado pelo governo brasileiro um documento para dar acesso aos agricultores familiares em diversas políticas públicas e mercados que é a Declaração de Aptidão ao Pronaf DAP, que segundo a Secretaria Especial de Agricultura Familiar e do Desenvolvimento Agrário Sead (2018) a DAP inclui agricultores familiares com rendas anuais de até $\mathrm{R} \$ 360$ mil. A DAP individual será um instrumento fundamental para o cadastro do produtor no Portal Web de Comercialização, já que um dos critérios do portal é incentivar o acesso dos produtos e serviços do agricultor familiar cadastrado.

Portanto, o referido Portal Web é uma inovação tecnológica que está sendo introduzida no meio rural e da pesca capixaba, que visa atuar como estratégia de gestão, marketing, agregação de valor e comercialização, o que propicia informações que poderão empoderar, tanto os produtores quanto os consumidores, o que remete às tecnologias sociais que incentivam a geração de renda, a inclusão produtiva e criativa, a segurança alimentar e nutricional de quem produz e de quem consome os alimentos anunciados no Portal, bem como, efetiva o circuito curto de comercialização, preços justos, eliminando assim os atravessadores. Dessa forma, promove tmabém a estruturação da cadeia produtiva agropecuária do Estado, as organizações associativas 
dos produtores e extrativistas, o que remete à transformação social das comunidades rurais, aquícolas e pesqueiras do Espírito Santo e ao alcance do desenvolvimento rural sustentável.

\section{Metodologia}

Para avaliar a usabilidade utilizou-se a avaliação cooperativa. Segundo Monk et al. (1993), a avaliação cooperativa é um método que identifica os pontos na interface que dificultam a interação do usuário com o sistema. Este método foi escolhido pela sua simplicidade de aplicação, pois não exige uma estrutura física complexa para a avaliação. Como o Incaper tem 80 escritórios em todos os 78 municípios capixabas, a princípio entendeu-se que essa capilaridade seria um grande ponto favorável para a pesquisa, mas o espaço físico da maioria desses escritórios é pequeno e com problemas de infraestrutura, como internet precária, o que dificultaria uma avaliação em um ambiente mais controlado. Portanto, foram realizados testes amostrais, em localidades com melhor acesso à internet e em regiões com um número significativo de agricultores familiares assistidos pela equipe multidisciplinar do Incaper.

Monk et al. (1993) recomenda fazer a avaliação cooperativa com usuários com perfil semelhante ao usuário típico do sistema. Um pré-teste foi realizado seguindo o que foi preconizado pelo autor, com quatro agricultores familiares que participaram da pesquisa no Escritório Local de Desenvolvimento Rural - ELDR do Incaper, localizado na cidade de Cariacica, ES, município com relevante atuação na comercialização dos produtos da agricultura familiar. Para este pré-teste foi preparado algumas tarefas para serem validadas, ou seja, as tarefas avaliaram as funções principais ou partes da interface que serão utilizadas diariamente pelo usuário.

Conforme Monk et al. (apud Simões, 2011, p.70) a avaliação do pré-teste e a avaliação do teste final seguiram as seguintes recomendações:

- Antes de o usuário chegar, é necessário fazer um teste no protótipo e certificar-se de que não há elementos que possam atrapalhar a realização da tarefa; ter uma folha com as tarefas; um meio para gravar as ações e as falas do usuário; e uma lista de questões que serão aplicadas no final da sessão;

- Quando o usuário chegar, é necessário deixar o usuário à vontade; relembrar ao usuário que é o sistema que está sendo avaliado; explicar ao usuário o processo da avaliação e introduzir os passos da tarefa para o usuário ter uma ideia geral do que ele vai fazer;

- Durante o processo de interação o usuário deve ter liberdade para discutir o sistema e esta discussão é conduzida de maneira informal; cada passo inesperado e comentários do usuário sobre a usabilidade devem ser anotados; o usuário deve ser encorajado a pensar em voz alta; o avaliador deve permitir que o usuário cometa erros e encontre problemas, mas não deve antecipá-los;

- Depois de finalizada a sessão, o usuário deve ter um tempo para falar do sistema. A gravação não deve ser interrompida nesta etapa, pois o usuário pode fazer algum comentário importante que não tenha sido dito durante o processo de interação;

- Para finalizar, realizar um resumo das observações, pois o importante é o avaliador anotar todos os detalhes relevantes que dificultaram o processo de interação, 
inclusive destacar os comportamentos inesperados e os comentários subjetivos sobre a interface.

Outros pontos relevantes para a seleção desse método são que o usuário é estimulado pelo avaliador a verbalizar de maneira informal os problemas encontrados na interface e isso deixa o usuário mais à vontade para apontar as barreiras de uso do portal. $E$ a facilidade de utilização do método, pois o procedimento é de baixo custo e pode ser aplicado a qualquer tipo de perfil de usuário, além de propiciar resultados rápidos e assertivos.

\section{A aplicação}

Um pré-teste foi realizado com quatro agricultores e para esta avaliação foi reservada uma sala com um computador desktop conectado a rede interna do Incaper para que os usuários pudessem ter acesso ao sistema do portal.

Os quatro agricultores eram do sexo masculino, com idade entre 25 a 45 anos. Três agricultores têm computador em casa e celular e somente um agricultor não faz uso de computador, mas este agricultor relatou que utiliza celular regularmente. As tarefas selecionadas para este perfil de usuário foram:

Tarefa 1: Fazer o cadastro no site;

Tarefa 2: Incluir um produto para venda e visualizar no sistema o produto que foi cadastrado;

Tarefa 3: Alterar a quantidade do produto cadastrado;

Tarefa 4: Incluir um frete solidário e visualizar um frete disponível.

Para o registro desse pré-teste foi utilizado uma câmera de vídeo caseira, papel e caneta. Durante todo o pré-teste os usuários foram estimulados a relatar todos os problemas encontrados na interface que dificultaram o uso do portal. O tempo médio de cada avaliação do perfil agricultor durou aproximadamente 40 minutos.

Após o pré-teste percebeu-se que a tarefas selecionadas estavam de acordo com as funções principais ou partes da interface que serão utilizadas diariamente pelos usuários selecionados.

Foram convidados cinco usuários agricultores para avaliação do teste de usabilidade. Esta avaliação ocorreu na cidade de Domingos Martins, ES no Centro Regional de Desenvolvimento Rural - CRDR do Incaper - Centro Serrano (Figura 2). Valem ressaltar que neste regional, se concentram os agricultores familiares que atuam principalmente com olerícolas, fruticultura, produtos agroecológicos e orgânicos e agroindustrializados, que abastecem todo o Brasil e participam também das exportações. Nessa região serrana capixaba, colonizadas pelos europeus, vale destacar as atividades do agroturismo e do turismo rural que são referências nacionais, o que justifica a escolha dos agricultores locais, pois é onde há mais interesse em oferecer os serviços da agricultura familiar no Portal Web. Somente quatro usuários agricultores comparecerem no dia da avaliação e os testes foram realizados em uma sala reservada com computador com uma câmera para gravação. 
Figura 2 - Usuário agricultor familiar realizando as tarefas no Portal Web

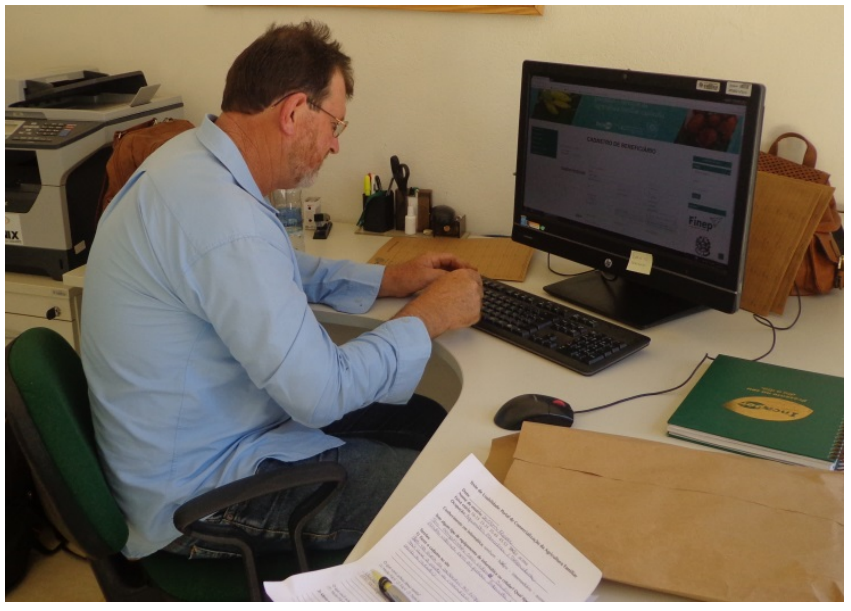

Fonte: o autor

Dois agricultores estavam na faixa etária de 55 a 65 anos. Um agricultor estava na faixa dos 25 a 35 anos e o outro agricultor na faixa de 45 a 55 anos. Dos quatro usuários, três deles tinham computador em casa com internet a rádio, mas não utilizavam o equipamento constantemente, $\mathrm{e}$ relataram que os filhos são quem mais utilizavam o computador e celular com internet.

Foi muito difícil aplicar o teste com usuários agricultores por causa do baixo conhecimento de informática que eles possuem, mas mesmo assim o sistema foi apresentado e todos os usuários fizeram alguns comentários relevantes sobre a usabilidade do sistema e sobre como este sistema vai ajudar na melhoria da comercialização da agricultura familiar. O tempo médio de cada avaliação durou aproximadamente 25 minutos.

\section{Resultados}

Para os usuários agricultores o portal apresentou os seguintes problemas:

\section{Tarefa 1: Fazer o cadastro no site}

Os usuários tiveram dificuldade para achar a palavra "Registre-se" para fazer cadastro no site. Os usuários não compreenderam o termo "login", que é um campo de formulário que fica posicionado acima da palavra "Registre-se", por esse motivo eles tentaram entrar no sistema antes de fazer o cadastro. Após várias tentativas, eles conseguiram entrar na página do formulário de cadastro (Figura 3). Nesta página, os usuários tiveram dificuldade para criar uma senha com oito dígitos e dificuldade para inserir o número da DAP (documento obrigatório para fazer registro no site). Ao salvar o formulário, os usuários ficaram frustrados ao perceber que deveriam preencher novamente o formulário, pois eles se esqueceram de preencher alguns campos obrigatórios. A maioria deles não sabe que o sinal "*" foi escolhido para representar campos obrigatórios. Os usuários também tiveram dificuldade de inserir o endereço, pois relataram que a propriedade rural não tem dados de endereço (rua, no, cep) definidos. Após o preenchimento do formulário, somente um usuário conseguiu visualizar se o cadastro foi realizado corretamente no site. 
Figura 3 - Página de Cadastro

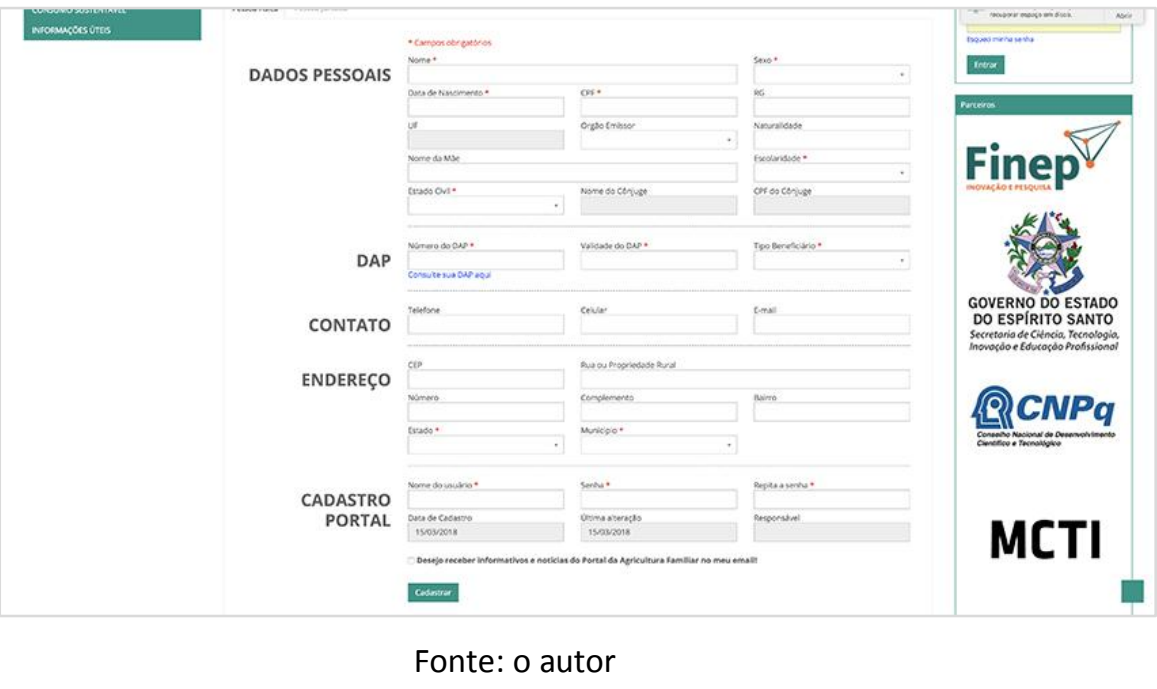

\section{Tarefa 2: Incluir um produto para a venda e visualizar o produto cadastrado}

Os usuários tiveram dificuldade para visualizar o item "Incluir um anúncio" no menu horizontal, eles ficaram atentos as opções do menu lateral. Neste menu não tem informações relevantes para a execução da tarefa. Dois usuários tiveram dificuldade de cadastrar a imagem, eles não conseguiram identificar o botão correto para essa funcionalidade. Um usuário não gostou da opção obrigatória para definir se o produto é orgânico. Os usuários ficaram confusos em selecionar o peso (em $\mathrm{Kg}$ ) de um produto. Dois usuários tiveram dificuldade de conhecer os campos obrigatórios do formulário. A posição dos campos "nome do contato e o telefone" não ficou destacada para os usuários, isso causou frustração nos usuários, pois eles não sabiam que informação deveria ser cadastrada. Todos os usuários tiveram dificuldade de visualizar os seus produtos cadastrados na página principal do site.

\section{Tarefa 3: Alterar o produto cadastrado}

Nenhum usuário conseguiu fazer esta tarefa. Os usuários não entenderam que precisavam voltar a "Área Restrita" do portal para fazer essa alteração.

\section{Tarefa 4: Incluir um frete e visualizar um frete solidário disponível}

Não tiveram dificuldade em incluir um frete ou visualizar um frete disponível. Entretanto, após a inclusão de um frete, todos os usuários ficaram na dúvida se o frete foi cadastrado.

Durante o cadastro dois usuários preencheram errado o cadastro de "Capacidade de Carga", eles selecionaram o sinal (-) que demonstra carga negativa.

No geral, os resultados demonstraram que o portal não manteve o usuário informado sobre o que está acontecendo esse fato deixou os usuários indecisos sobre toda a operação. 0 portal também não utiliza termos familiares e não permite o usuário desfazer ações de forma intuitiva. As mensagens de erro não estão visíveis e não ajudam o usuário a resolver um problema encontrado.

\section{Recomendações}

Considerando os resultados encontrados recomendam-se as seguintes ações: 


\section{Tarefa 1: Fazer o cadastro no site}

- Mudar a palavra "Registre" para o termo "Cadastre-se aqui" e mudar o posicionamento desse link no site, a recomendação é que o link fique em formato de botão e posicionado acima do campo de "login" e com um tamanho maior.

- O termo "login" deve ser trocado por "Digite aqui seu nome".

- Mudar a forma de sinalizar (“*”) os campos obrigatórios no formulário de cadastro. Recomenda-se deixar por escrito "Campo Obrigatório" ao lado do título do campo do formulário.

- Diminuir a quantidade de números para criar um senha.

- Integrar o CPF do usuário agricultor com o número da DAP;

- Colocar o campo endereço como obrigatório, mas retirar essa obrigatoriedade para o CEP, pois nem todas as propriedades rurais dispõem do número do CEP. Inserir um campo "referência" para ajudar na localização da propriedade;

- Apresentar a mensagem de "Cadastro efetuado com sucesso" abaixo do formulário de cadastro.

\section{Tarefa 2: Incluir um produto para a venda e visualizar o produto cadastrado}

- Colocar as funcionalidades do menu horizontal no menu lateral;

- Trocar o termo "Incluir Anúncio" pelo termo "Quero vender";

- Mudar o termo "Enviar imagem" por "Cadastrar foto do produto";

- Retirar a obrigatoriedade da opção "produto orgânico";

- Sinalizar os campos obrigatórios;

- Retirar a listagem de categorias de produtos para cadastro;

\section{Tarefa 3: Alterar o produto cadastrado}

- Verificar uma outra forma do usuário voltar a "Área Restrita". Sugere-se colocar um botão "voltar" na página ou criar uma área para o perfil do usuário no topo do sistema. Recomenda-se refazer outro teste de usabilidade para avaliar essa alteração;

- Acertar os erros de cadastro de produto no sistema.

\section{Tarefa 4: Incluir um frete e visualizar um frete disponível}

- Incluir uma mensagem de aviso para informar o cadastro do frete;

- Simplificar o cadastro da carga do veículo;

No início da pesquisa os usuários foram questionados que ferramenta eles utilizam para acessar a internet e a maioria respondeu que usa o celular. O portal é responsivo, ou seja, se adapta a vários tamanhos de tela, mas esta avaliação foi realizada em um computador desktop, recomenda-se fazer novo teste de usabilidade utilizando celular.

Novos testes de usabilidade também deverão ser realizados para os outros grupos de usuários, principalmente com o usuário "comprador", pois sem este usuário a comercialização não será concluída. 
Recomenda-se também criar uma imagem para representar o passo-a-passo de como funciona o sistema, pois não há uma ajuda ao usuário no portal.

Um agricultor recomendou que o sistema gerasse um relatório sobre a quantidade de vendas, pois esses dados da comercialização podem ajudá-lo a conseguir financiamentos.

\section{Conclusão}

A avaliação cooperativa foi eficiente para coletar as informações sobre os problemas ocorridos durante o uso do portal pelos agricultores. Através dessa avaliação foi possível mostrar as falhas de uso do portal, observar as reações dos usuários, apontar as soluções para melhorar o design das telas, adaptar as terminologias para a realidade do usuário investigado e, principalmente, melhorar a forma de interação do usuário com o portal.

No início da avaliação, os usuários ficaram desconfiados, pois nunca tinham sido convidados para esse tipo de avaliação. Após a explicação de como seria o teste e qual era o objetivo do portal, os usuários ficaram bem à vontade para relatar todos os problemas de uso. 0 tempo dessa conversa inicial demorou mais do que o tempo para a realização do teste, mas esse momento foi fundamental para conhecer um pouco sobre as características sociais, culturais e econômicas dos agricultores. Um próximo passo para esta pesquisa é aplicar outras técnicas ergonômicas que possam identificar melhor essas características e de que forma essas características influenciam em todo esse processo de interação, design e comunicação.

Além de apontar os pontos de bloqueio de usabilidade da interface, a avaliação trouxe novas interpretações para as funcionalidades do portal. Um exemplo foi o usuário que não conseguiu completar o teste por causa do baixo conhecimento que ele tem em informática. Este usuário trouxe uma ideia que ajudaria muito no processo de comercialização, ele sugeriu a inclusão do perfil do agricultor no portal, ou seja, uma área para colocar as características da produção e da região agrícola. Este fato vai de encontro ao que diz o autor Frederich (1988) que afirma que os agricultores não devem ser considerados ignorantes pelo fato de não conhecer processos tecnológicos, pois quando o agricultor é convidado a participar de uma comunicação mais colaborativa ele consegue trazer boas soluções que vão contribuir com o desenvolvimento do campo.

Cabe enfatizar que os agricultores gostaram muito da proposta do portal, eles acreditam que esta ferramenta vai contribuir muito com a comercialização dos produtos dentro do Estado do Espírito Santo, mas os resultados demonstraram que a ferramenta precisa de ajustes para ser utilizada de forma segura, eficaz, eficiente e satisfatória conforme determina Preece et al. (2005).

\section{Referências}

BRASIL. LEI 11.326/2006, de 24 de julho de 2006. Estabelece as diretrizes para a formulação da Política Nacional da Agricultura Familiar e Empreendimentos Familiares Rurais. Diário Oficial da União. Brasília, DF, 25 jul. 2006. Disponível em: < https://www.planalto.gov.br/ccivil_03/_Ato2004-2006/2006/Lei/L11326.htm> Acesso em: 07 mar. 2018.

CAUS, T. Incaper lança inovações tecnológicas e sociais para a agricultura familiar. Disponível em: $<$ https://incaper.es.gov.br/Not\%C3\%ADcia/incaper-lanca-inovacoes-tecnologicas-e-sociais-para-aagricultura-familiar> Acesso em: 07 de mar. 2018. 
FRIEDRICH, O. A. Comunicação rural: proposição crítica de uma nova concepção. 2 ed. Brasília: EMBRATER, 1988.

IBGE - INSTITUTO BRASILEIRO DE GEOGRAFIA E ESTATÍ́sTICA. Censo agropecuário 2006. Rio de Janeiro: IBGE, 2006a.

<https://biblioteca.ibge.gov.br/visualizacao/periodicos/50/agro_2006_agricultura_familiar.pdf> Acesso em: 07 de mar. 2018.

NORMAN, D.A. O design do dia-a-dia. Rio de Janeiro: Rocco, 2006.

MONK, A.; WRIGHT, P.; HABER, J. DAVENPORT, L. Improving your human-computer interface: a practical technique. London: Prentice-Hall, 1993.

MORAES, A. (Org.). Design e Avaliação de Interface. Rio de Janeiro: IUSER, 2006.

MORAES, A. ; MONT'ALVÃO, C. R. ; RUSSO, B. ; HEKKERT, P. ; NIEMEYER, L. ; DAMAZIO, V. ; LIMA, J. ; MEYER, G. ; KINDLEIN JR., W. ; COLLET, I. B. ; DISCHINGER, M. C. T. ; MEDEIROS, W. G. ; ASHTON, P. . Design Ergonomia Emoção. 1. ed. Rio de Janeiro: FAPERJ/ MAUAD X, 2008.

MORAES, A.de; MONT'ALVÃO, C. Ergonomia: conceitos e aplicações. Teresópolis: 2AB. 4 ed., 2012 PREECE, J. et al. Design de interação homem-computador. Porto Alegre: Bookman, 2005.

SANTA ROSA, J. G.; MORAES, A. Avaliação e Projeto no Design de Interfaces. Teresópolis: 2AB, 2008.

Secretaria de Agricultura, Abastecimento, Aquicultura e Pesca do Estado do Espírito Santo. Disponível em: <https://seag.es.gov.br/governo-aumenta-parceria-com-agricultores-par> Acesso em: 07 de mar. 2018.

SIMÕES, A. P. Avaliação ergonômica da usabilidade do ambiente virtual de aprendizagem: CEADIFES/ES, um estudo de caso. Disponível em:<http://www2.dbd.pucrio.br/pergamum/biblioteca/php/mostrateses.php?open=1\&arqtese=0912485_2011_Indice.html> Acesso em: 07 de mar. 2018.

WANDERLEY, M. N. B. "Franja periférica", "Pobres do campo", "Camponeses": dilemas da inclusão social dos pequenos agricultores familiares.IN:DELGADO, G. C.; BERGAMASCO, S. M. P. P. (Orgs.) Agricultura familiar brasileira: desafios e perspectivas de futuro. Brasília: Ministério do Desenvolvimento Agrário, 2017, p. 65-83. 